\title{
BROUGHT BY DEGREES: A FOCUS ON THE CURRENT INDICATORS OF LEAN 'SMARTNESS' IN SMART CITIES
}

\author{
Dave Collins ${ }^{1}$, Agnar Johansen², Bo Terje Kalsaas ${ }^{3}$, Alenka Temeljotov-Salaj ${ }^{4}$, and \\ Mohammed Hamdy ${ }^{5}$
}

\begin{abstract}
The purpose of this paper is to look at the indicators to which a city can be considered to be a smart city based upon the degree it meets specific indicators within the categories of 'Social Smartness', 'Technological Smartness' and 'Environmental Smartness'. The data collection for this paper was conducted through desk research in academic and nonacademic articles and publications that focus on smart cities and their associated indicators. This study found out common factors based upon the indicators studied. 'Social Smartness' had a focus on the quality of life, civic engagement and wellbeing. 'Technological Smartness' was centric on flexible technology, well utilised and defined applied technology and data. 'Environmental Smartness' was focused on optimisation, waste management and sustainable thinking. This study offers possibilities to advance Lean thinking by looking at indicators to attribute a degree of 'Smartness' to cities which in turn will optimise the development and operation of a Smart City and Smart Districts.
\end{abstract}

\section{KEYWORDS}

Lean thinking, smart cities, smart cities indicators, social indicators, sustainability.

\section{SMARTNESS IN SMart Cities}

With three-quarters of the world expected to be living in denser urban areas by 2050 (Alawadhi et al., 2012, p.40), it is vital to focus studies on sustainability, welfare and resource management on the experience within the world's cities. Historically, cities were protective entities for trade and growth with their primary needs being to protect their citizens from invaders, promote trade and ensure the people had enough sources to

Post-Doctoral Fellow, Department of Civil and Environmental Engineering, Norwegian University of Science and Technology (NTNU), Trondheim, Norway, 0047 92501501, david.collins@ntnu.no, orcid.org/0000-0003-0290-0486

2 Professor, Department of Civil and Environmental Engineering, Norwegian University of Science and Technology (NTNU), Trondheim, Norway, 0047 93058741, a.johansen@ntnu.no, orcid.org/00000003-0063-3679

3 Professor, Department of Engineering Sciences, University of Agder, Kristiansand, Norway, 0047 97082582, bo.t.kalsaas@ uia.no, orcid.org/0000-0003-4383-1683

4 Professor, Department of Civil and Environmental Engineering, Norwegian University of Science and Technology (NTNU), Trondheim, Norway, 0047 46445072, alenka.temeljotov-salaj@ntnu.no, orcid.org/0000-0002-4139-5278

5 Associate Professor, Department of Civil and Environmental Engineering, Norwegian University of Science and Technology (NTNU), Trondheim, Norway, 0047 92052876, mohamed.hamdy@ ntnu.no, orcid.org/0000-0002-3472-0386 
survive. In many respects (except the first point), these needs remain mostly unchanged. Lean was first coined by Krafcik (1988) addressing Toyota's production system. "The machine that changed the world" by Womack et al. (1990) was significant for the development of lean practices in western countries. A central contribution was also "Lean thinking. Banish waste and create wealth in your corporation" (Womack and Jones, 1996) and the "Toyota Way" (Liker, 2003).

In the 1990s Lean was brought into construction and the built environment (Koskela, 2000; Ballard, 2000). The ideas surrounding it with regards to reducing waste, increase flow and fostering productivity have existed since the beginning of the development of cities. A city is naturally not a whole entity in itself but is a scalable one with differing needs and considerations at the urban planning level, community level, building level and citizen level. This sustainability ambition is supported by radical and challenging goals, with the European Commission setting the goal of 100 Smart Cities in Europe by 2030 (EC, 2020, p.4). A goal as ambitious as this does not just require a robust definition of what constitutes a Smart City, but also benchmarks, indicators and holistic thinking. This thinking also has to be found at the district and neighbourhood level to understand the differences and bespokeness of smart initiatives. Whilst a study focusing on the indicators of what constitutes a smart city is not new, there is a deficit in terms of how this can be applied to 'indicators of smartness' as opposed to a more binary discussion on whether simply a city is smart or not. To cite an example, Castelnovo et al. (2016) state that a city can be smart depending on the degree to which it blends ICT, and smart governance (Castelnovo et al., 2016, p.735). Whilst this can be considered to be more of a binary absolute in terms of field compatibility, others offer similar binary outcomes but at different levels of the city. The European Commission (EC) for example has developed the 'Smart Readiness Indicator' to establish whether a building could be considered smart or not (Castevolo et al., 2016). Whilst these indicators are less binary than those mentioned by Castelovo et al. (2016) they are at the building and not the city level. An increasingly developing field and concept that attempt to tackle these issues on multiples levels are that of Smart Cities. A challenge for scholars in this aspect (as is the case for other fields at a similar level of development) is that Smart Cities encompass many fields within it (such as urban planning, architecture, social sciences and facilities management) as well as suffer from the complications associated with it lacking a universally accepted definition. An increased focus on 'Smartness' in the context of cities is becoming of increasing importance and relevance in modern development. This in turn places stresses on existing infrastructure as we scramble to find ways to ensure the safety of citizens, as well as ensure adequate access to safe water, food and energy. With this in mind, Lean thinking may be fruitful in terms of applying this to smart cities, especially when it comes to the processes of transforming the existing built environment to smart cities in a valuecreating perspective. While the mainstream Lean construction researcher for the most part address production and customer value creation (e.g. Koskela, 2000; and Ballard, 2000), Herscovici (2018) take it further to smart cities and argues that Lean thinking encourages the quest for excellence by constantly re-evaluating and improving infrastructure whilst ensuring stakeholder value maximisation and removing unevenness and waste, with will foster Smart Cities growth but ensuring that new and existing processes operate under this model (Herscovici, 2018, pp.321-322). Our stand is the values we find in the smart city concept will benefit from organising the processes of transforming and maintain existing neighbourhoods and cities to be smarter. The two concepts fit well regarding principles (Skaar et al., 2020) like respect for people (Liker 2004), involvement (Ballard, 
2000), learning (Kalsaas, 2012), relational contracts and Target Value Design (Zimina et al., 2012). In this paper, we will look at existing indicators of how smart a city can be, show if aspects of a city are smart, but also the indicators of 'smartness' a city can be considered to possess.

In this study we will address the following research questions:

- Research Question 1 - What are current indicators exist to gauge whether a city is smart?

- Research Question 2 - How can these indicators be applied to demonstrate smartness within a city?

Firstly, this paper will look into the methodological approach before moving onto theory regarding defining a smart city in the context of this paper, as well as indicators. The theoretical framework for this paper also orientates itself towards the principles, before moving onto the indicator of Smart Cities. The paper is then structured by dividing the indicators between the categories of 'Social', 'Technological', 'Environmental' smartness. These categories were chosen due to the links between the common sustainability framework of the 'triple bottom line' as well as technological aspects that are more commonly understood in existing smart cities definitions The paper will then move on to provide a conceptual framework as to how this can be applied to give smart cities indicators of 'smartness'.

\section{Methodology AND ReSEARCh DESIGN}

This paper is a literature review consisting of desk research conducted on literature from academic and non-academic sources. This literature review was compiled as part of the research project Citizens a Pilots in Smart Cities (CaPs).

\section{Data Collection and Analysis}

Literature was primarily sourced through Google Scholar in the case of academic literature, and Google in the case of non-academic literature, with the disciplines of project management, smart cities, urban planning and sustainability being the primary focuses for inclusion. The specific papers chosen for inclusion here were selected due to their status in respected peer-review journals and citation level as well as their publication from worldwide respected institutions such as the United Nations. This approach was taken concerning the fact that a new definition of 'smartness in smart cities' is not possible in a paper of this length, however, there is significant scope to offer the beginning of a framework by which one could be developed in a further publication. The indicators were then organised under the categories of 'Socially Smart', 'Technologically Smart' and 'Environmentally Smart'. The categories were chosen as a set that was a hybrid of the triple bottom line of sustainability ('economic', 'social' and 'environmental' sustainability) combined with the Deakin and Al Waer's (2011) 'Three Factors' of what defines a smart city, which will be outlined in the next chapter. These three categories also act as a theoretical framework for the outcomes of the literature search and were sourced from a variety of publications (Deakin et al., 2011, p.141), (Joshi et al., 2016), (UN, 2017).

\section{How to Analyse The Smartness of Cities?}

In this section, we will briefly out some definitions frameworks that will relevant for a contextual understanding of the findings in this paper. 


\section{Definition of Smart Cities}

Whilst the study of smart cities is becoming increasingly established a discipline, it still suffers from the challenge associated with not having a universally accepted definition. For this study, the definition by Deakin and Al Waer (2011) have been used According to the authors, a smart city can be considered smart if it contains four factors. Firstly, the implementation of an extensive range of digital and electronic technologies in cities and their communities. Secondly, the usage of information technology to change the lives and work of people living in these areas. Thirdly, implementing a wider spread of the use of these technologies and others at the government level. And finally, using technology to bring people together to innovate and enhance knowledge (Deakin et al., 2011, p.141). In terms of a definition that reflects indicators more associated with sustainability, CityKeys published a report in 2017 in cooperation with the EU Commission and Horizon 2020 outline their definition. This definition follows the triple bottom line of sustainability of social, economic and environmental sustainability. In terms of what constitutes a Smart City, they state that it must improve the quality of life for its inhabitants (including commuters, students and visitors) (social), improve resource efficiency to decrease pressure in the environment (environmental), a green economy focused on innovation (economic) and develop local democracy and governance (social) (Bosch et al., 2017, p7).

\section{Indicators}

It is also important moving to understand what constitutes an indicator in the context of this paper. According to the Collins English dictionary, an indicator can be considered to be a "measurement or value which gives you an idea of what something is like" (Collins, 2021). Whilst this definition does not come from a scientific publication, it is relevant to this study in the sense that the authors consider an indicator to demonstrate whether a concept (such as a smart city) is what it claims to be by evaluating it against commonly accepted factors or processes that are the link to a broad definition of it. Aside from what an indicator is in a more literal sense, there are also different kinds of indicator that are placed in different areas of a process or system. Referring once again to CityKeys, their typology consists of 'Input Indicators' that refer to the resources needed for implementation of an activity, 'Process Indicators' to indicate whether an activity took place, 'Output Indicators' that add more detail concerning the product, 'Outcome Indicators' that refer to measuring the intermediate results generated by the outcome, and 'Impact Indicators' that measure the quality and long term results of the program (Bosch et al., 2017, p. 15).

\section{INDICATORS OF SMARTNESS - THE FINDINGS}

\section{Socially Smart}

Social indicators for the Smartness of cities is prevalent in both academic and industry literature. If a Smart City can be considered to be an investment in social capital to an extent (Purnomo et al., 2016, p.161), then social indicators are entrenched in a conceptual Smart Cities framework. Many such indicators can be found in academic literature. Purnomo et al. (2016) in their systematic literature review on Smart Cities discovered several social indicators. They categorised these indicators into six main sections, with generally 3 levels of more specific sub-indicators. In terms of relevant social indicators relevant to this section, they can consider being 'Smart Living' and 'Smart People'. 'Smart Living' contains the subcategories of 'Social security and safety, 'Housing Quality' and 'Public Transport System'. The category of 'Smart People' contains the categories 
of 'Education System and Facilities' and 'Creativity' (Purnomo et al., 2016, p. 163). An interesting observation of these indicators is that many of the aspects of 'Smart Living' could be considered to straddle both social and structural smartness categories, which further shows the challenges associated with looking for binary indicators. Malek et al. (2021) have also looked at socially-focused indicators, however from a more formalised citizen-centric perspective. The outcomes of their review reveal indicators that are almost as much do with civic governance as they are with social smartness. Their indicators are 'Focus on citizens' needs, not just technology', 'Decision through consensus with citizens ', 'Learn from users/citizens', 'Power needs to be delegated', 'Freedom to participate', 'Volunteers needed', 'Build good relationships' and 'mutual trust' (Malek et al., 2021, p.10). When comparing the different indicators of both authors, it is indicative of social smartness being not just about respecting and improving social welfare in smart cities, but also ensuring that citizens engagement in this is well defined and applied. The European Commission are an example of a non-academic actor that has considered the social aspects of smart cities and has developed indicators for them. Whilst less specific and detailed than those found in the previous citation from academia, they describe their indicators in the form of 8 criteria of smart cities preparedness levels. Amongst these 8 are two socially relevant ones consisting of 'citizen engagement and 'social models'. As with academic authors previously, this focuses both on a combination of wellbeing in a city and being civically accountable through citizen participation. The European Union have also considered these aspects but from a slightly different perspective of social innovation. In a 2012 report the Urbach section of the EU stated that can be achieved by three focuses - 'Social Demand Innovations' (responding to social demands that haven't been traditionally addressed by the market of existing institutions), 'Societal Challenge' (innovations for a society by integrating social, environmental and environmental aspects), and 'Systemic Change' (encompassing the other two and achieving it through organisational development and the relationship between institutions and stakeholders) ('SMART CITIES Citizen Innovation in Smart Cities, 2012. p.6). Unlike previous indicators, these social innovation categories are clearer on their links to sustainability whilst still encompassing the themes of previous indicators.

\section{Technologically Smart}

When considering what constitutes a Smart City, many a core attribute is that of technological implementation in the wider cityscape. The leap in technology in cities as well as the devices themselves have seen considerable significant advancement in recent years, with visualisation mechanism, sensors, virtual reality, augmented reality and artificial intelligence all playing a part (Jamei, 2005). With this in mind, it is crucial to understand the incorporation of technological smartness. This is recognised by Borsekova et al. (2018), who states that for a city to be 'smart' it should utilise technological capital (as well as human and collective capital) for the enhancement and development of the urban environment (Borsekova et al., 2018, p. 18).

In terms of indicators found in academic literature, there numerous aspects that can be cited, and a small selection of which shall be discussed here. Park et al. (2018) have Smart Cities indicators that cover several topics, including those related to technological smartness. They state that a major component of a Smart City is the integration of 'Key Industry' and 'City Infrastructure' as a component. Within 'Key Industry' is Smart Buildings and Smart Facilities, whilst 'City Infrastructure' contains operation systems, sensor networks and smart devices which in turn link to control systems, data analysis, 
web services and telecommunications platforms (Park et al., 2018, p.2). These indicators (as superficially indicative as they are due to lack of KPI's) do not just describe specific technological services, but also a degree of how they feed into real work possibilities for citizens (e.g. interactive web services). To cite another example from academia, Joshi et al. (2016) also developed their indicators, which also encompass the technological. They propose six pillars that constitute a Smart City - 'Social', 'Management', 'Economy', 'Legal', 'Technological', and 'Sustainability' (Joshi et al., 2016, p.903). With regards to the technological pillar, they claim that this must encompass several qualities. They cite these as 'Big Data', 'Interconnected devices', 'Information and Communication Technology' and an 'Amalgamation of these Drivers' (Joshi et al., 2016, p.906). Indicators of technological smartness can also be found in literature found outside of academia. CityKeys state in their report their own set of indicators. Several pages into the report they offer indicators on three categories - 'Input Indicators', 'Process Indicators' and 'Output Indicators'. In terms of those considered relevant for technological smartness, in 'Process Indicators' they have diversity in ways to contact the municipality, improved digital literacy of the elderly and the standardisation of interfaces. In 'Output Indicators' contain the openness and quality of data sets, parking guidance systems, and the likes of smart meters (Bosch et al., 2017, pp.16-27). As mentioned earlier, building-related Smart City Readiness indicators have been developed in the conjunction with the EC. As also mentioned, whilst designed to consider the building level, they could be considered applicable to the wider city level. The expression of indicators is much more focused on functionality in the context of smart city readiness, as well as flexibility. These functionality aspects are the ability to maintain energy performance and operation, adaptive buildings that are responsive to the needs of occupants as well as be flexible in terms of energy (EC, 2019, P.6). In terms of how this can be applied to technological smartness at the city level, these indicate that a technologically smart city is energy conscious, flexible and adaptive to the needs of citizens through a well-defined methodology.

\section{Environmental Smartness in Urban Areas}

In many theoretical and practical discussions on Smart Cities, it is becoming increasingly important not just to consider, but to entrench sustainability and environmental considerations. Six sustainability indicators were published by Petrova-Antonova et al. (2018) which were specifically tailored for consideration in the context of a smart city. They describe this in the context of a larger encompassing thematic area called 'Smart Nature'. These six categories consist of 'Water', 'Pollution', 'Waste', 'Energy', 'Land' and 'Green Environment' (Petrova-Antonova et al., 2018, p. 488). In later more detailed descriptions of these indicators, it is clear that they intend not just to improve a Smart Cities environmental credibility, but also to improve the quality of life of citizens by reducing waste and optimising processes. Verma et al. (2018) are even more clear with regards to their indicators by stating the words 'sustainability indicators' clearly in their subject headline. In their article, they define sustainable urban development as having the qualities of 'improving quality of life through social interaction', 'easy access through a wide range of services, 'minimising energy consumption, 'sustainable transport' and 'environmental protection and restoration' (Verma et al., 2018, p.284). As with the previous citation, there is a clear link between sustainability being not just about environmental improvement, but also well-being and waste reduction. It is also important to consider not just smart cities on the city level, the component aspects at the building 
level that also combine the likes of technology. One example is Green Leasing where smart metres, technology and human behaviour come together to encourage sustainable building development in the rental market (Collins, 2018, p. 185). In Table 1 we have summarised the key principles based on the literature review, which are related to a selection of Lean principles.

Table 1 How to define a smart city

\begin{tabular}{|c|c|c|}
\hline $\begin{array}{l}\text { Socially } \\
\text { smart }\end{array}$ & Technologically smart & $\begin{array}{l}\text { Environmentally } \\
\text { Smart }\end{array}$ \\
\hline \multicolumn{3}{|l|}{ Citizen Participation } \\
\hline $\begin{array}{l}\text { Educated and upskilled } \\
\text { citizens }\end{array}$ & $\begin{array}{l}\text { Feasible technological } \\
\text { infrastructure }\end{array}$ & Initiatives to lower the carbon footprint \\
\hline $\begin{array}{l}\text { People-Centred } \\
\text { Processes }\end{array}$ & $\begin{array}{l}\text { Well managed and } \\
\text { utilised data }\end{array}$ & $\begin{array}{l}\text { Utilise data and technology to reduce } \\
\text { emissions on roads and in buildings }\end{array}$ \\
\hline $\begin{array}{l}\text { High quality of life and } \\
\text { consideration of well } \\
\text { being }\end{array}$ & Possibilities to learn & $\begin{array}{c}\text { A more environmentally considerate } \\
\text { society based on improved resource } \\
\text { management and security }\end{array}$ \\
\hline $\begin{array}{l}\text { beIng } \\
\text { Technologically } \\
\text { engaged citizens } \\
\text { Smart Governance }\end{array}$ & $\begin{array}{l}\text { Safety and resource } \\
\text { management a priority } \\
\text { Respect for data, } \\
\text { privacy and well being }\end{array}$ & $\begin{array}{c}\text { Focus on quality of life in a more } \\
\text { sustainable society }\end{array}$ \\
\hline
\end{tabular}

The listed principles in Table 1 is output or outcome-based. Koskela and Kagioglou (2006) understand output as a "thing", e.g. a new building or a neighbourhood, while outcome includes the "processes" of usage of it and the value regarding operation and maintenance. We can also expand that outcome aspect to external impacts on the environment, city life and business. We see the Lean associated with smart cities foremost as guiding principles (Skaar et al., 2020) to encourage the output/outcome addressed in Table 1. Lean principles can guide us regarding how to organise and conduct complex creative and rather wicked design and development processes (Kalsaas, 2020) to reach the values in Smart cities. Moreover, the transformation processes should be based on the same values as the outcome we want to achieve, which is the case between Smart cities and Lean. Keywords in that context is respect for people, involvement, learning, continuous improvement and more radical innovation (Koskela, 1992), reduce waste, creating value for the participants and end-users.

\section{CONCLUDING DiscuSsion}

This paper has intended to illustrate which indicators can be used to determine the smartness of cities as well as show the commonalities between them to gauge the degree to which a city can be considered Smart based on the implementation of them.

\section{Research Question 1 - What are the current indicators?}

In terms of current indicators, however, many common factors exist between them that allows for a degree of simplification for later utility. 
Table 2 - Indicator Commonalities

\begin{tabular}{|c|c|c|}
\hline $\begin{array}{l}\text { Smartness } \\
\text { Categories }\end{array}$ & $\begin{array}{l}\text { Thematic } \\
\text { Area }\end{array}$ & Indicators \\
\hline \multirow{3}{*}{$\begin{array}{l}\text { Socially } \\
\text { smartness }\end{array}$} & Civic Engagement & $\begin{array}{c}\text { Public participation, Citizen centred city } \\
\text { development, Easy to use digital engagement, } \\
\text { Smart Governance }\end{array}$ \\
\hline & Quality of Life & $\begin{array}{l}\text { Services access, Improvements to health, } \\
\text { Increased mobility, Infrastructure }\end{array}$ \\
\hline & Wellbeing & $\begin{array}{c}\text { Happiness, connected services, change } \\
\text { management }\end{array}$ \\
\hline \multirow{3}{*}{$\begin{array}{l}\text { Technologically } \\
\text { Smartness }\end{array}$} & Flexible Technology & $\begin{array}{c}\text { Adaptive to changing needs, multi-use data, } \\
\text { accessible technology }\end{array}$ \\
\hline & Utilisation Data & Define usage, respect for privacy \\
\hline & Defined Application & $\begin{array}{c}\text { Stakeholder relevant, data plan, citizen access to } \\
\text { technology and data }\end{array}$ \\
\hline \multirow{3}{*}{$\begin{array}{l}\text { Environmentally } \\
\text { smartness }\end{array}$} & Optimisation/Tradeoff & $\begin{array}{l}\text { Ongoing reappraisal of infrastructure, constantly } \\
\text { adjustment to resource use }\end{array}$ \\
\hline & Waste Management & $\begin{array}{c}\text { Recycling, building adaption and reuse, Citywide } \\
\text { waste plan }\end{array}$ \\
\hline & Sustainable Thinking & $\begin{array}{l}\text { Reducing emissions, advanced public transport } \\
\text { infrastructure, microgeneration, renewable energy }\end{array}$ \\
\hline
\end{tabular}

Table 2 represents not the indicators overall, but the commonalities that can be gauged to interpret the degree to which a city can be considered smart. By ensuring that a city has the possibility of holistically meeting some of these wider indicative categories it can turn can more holistically smart. In this table, the reader can see the indicative properties of each thematic area, which offers scope for further research the explore this 'smartness' with KPI's and more advanced benchmarking. In the context of this paper, however, table 2 offers weight and validity to these thematic areas beyond the themes alone.

\section{Research Question 2 - How can these indicators be applied to demonstrate smartness?}

An attempt by a city to meet with these aspects 'inter category' can have the possibility to improve the indicators where a city can be considered to be smart. In the case of Socially Smart, a city with a high level of citizen engagement and participation aimed at improving the well-being quality of life of its citizens can be considered successful. If a city contains a high level of flexible technology with well utilised and applied supporting data, then it can be considered to be technologically smart. An environmentally smart city can gauge its level of smartness on the degree to which it reduced waste, optimised services and quality of life with environmental considerations at its heart. This paper has shown that not all Smart Cities are created equal and that it needs to incorporate a variety of indicators in many themes which in essence are impossible to completely cover in a paper of this length. However, what this indicative data has demonstrated is that there is a real possibility in research not just to expand the scope and definition of what a smart city is, but also to show that no definition is binary and a city can be possibly 'smart by degrees'. 
It would be interesting in further research to look from an increasingly micro perspective to see if city districts can have different levels of smartness and that each district or city will need a bespoke framework of its own by which to improve smartness. It is hoped that academics and non-academic researchers and visionaries can use the data in this paper not just to further entrench Lean thinking into smart cities, but possibly further incorporate other fields into the discussions and view cities not just as projects, but as canvases.

\section{REFERENCES}

Alawadhi, S., et al. (2012). Building understanding of smart city initiatives. International conference on electronic government, Springer.

Ballard, G. (2000). The Last Planner System of Production Control. School of Civil Engineering, The University of Birmingham, UK.

Borsekova, K., et al. (2018). "Functionality between the size and indicators of smart cities: A research challenge with policy implications." Cities, 78: 17-26.

Bosch. P, S. J., Vera Rovers (TNO), Hans-Martin Neumann (AIT), Miimu and A. a. A. H. (VTT). (2017). CITYkeys indicators for smart city projects and smart cities. dataplan.info, CityKeys in conjunction with the EU Commission and Horizon 2020.

Carneiro, S. B. d. M., et al. (2012). Lean and green: a relationship matrix, Annual Conference of the International Group for Lean Construction.

Castelnovo, W., et al. (2016). "Smart cities governance: The need for a holistic approach to assessing urban participatory policy making." Social Science Computer Review, 34 (6): 724-739.

Collins (2021). "Definition of 'indicator'." Retrieved 19th February, 2021, from https://www.collinsdictionary.com/dictionary/english/indicator\#: :text=An\%20indicato r\%20is\%20a\%20measurement,guide\%20More\%20Synonyms\%20of\%20indicator.

Collins, D. (2018). "Green leases and green leasing in theory and in practice: a state of the art review." Facilities.

Deakin, M. and H. Al Waer (2011). "From intelligent to smart cities." Intelligent Buildings International, 3(3): 140-152.

EC (2019). Discussion document - definition and calculation methodology of the smart readiness indicator. ec.europa.eu, European Commission: 15.

Herscovici, A. (2018). "New development: Lean Thinking in smart cities." Public Money \& Management, 38(4): 320-324.

Kalsaas, B. T. (2012). The Last Planner System Style of Planning: Its Basis in Learning Theory. Journal of Engineering, Project, and Production Management, 2(2), 88- 100. doi:10.32738/jeppm.201207.0005.

Kalsaas, B.T. (2020). Lean Construction: A management model for interdependencies in detailed design. In, Tzortzopoulos, P., Kagioglon, M. and Koskela, L. (Eds), Lean Construction. Core Concepts and New Frontiers, (pp. 209-229). Huddersfield: Routledge.

Koskela, L. (1992). Application of the new production philosophy to construction, CIFE Technical report \#72, Stanford University.

Koskela, L. (2000). An Exploration towards a Production Theory and its Application to Construction. VTT Technical Research Centre of Finland.

Koskela, L. and M. Kagioglou (2006). On the Metaphysics of Management. 14th Annual Conference of the International Group for Lean Construction, Santiago, Chile. 
Krafcik, J. F. (1988). Triumph of the Lean Production System. I Sloan Management Review, Volume 30.

Liker, J. K. (2004). The Toyota way : 14 management principles from the world's greatest manufacturer: New York : McGraw-Hill, [2004] @2004.

IEC (2019). "Smart and Sustainable Cities." Retrieved 22 May, 2019, from https://www.iec.ch/smartcitie.

Jamei, E., et al. (2017). "Investigating the role of virtual reality in planning for sustainable smart cities." Sustainability 9(11): 2006.

Joshi, S., et al. (2016). "Developing smart cities: An integrated framework." Procedia Computer Science, 93: 902-909.

Malek, J. A., et al. (2021). "Social Inclusion Indicators for Building Citizen-Centric Smart Cities: A Systematic Literature Review." Sustainability 13(1): 376.

Park, E., et al. (2018). "The role of Internet of Things (IoT) in smart cities: Technology roadmap-oriented approaches." Sustainability 10(5): 1388.

Petrova-Antonova, D. and S. Ilieva (2018). Smart Cities Evaluation-A Survey of Performance and Sustainability Indicators. 2018 44th Euromicro Conference on Software Engineering and Advanced Applications (SEAA), IEEE.

Purnomo, F. and H. Prabowo (2016). "Smart city indicators: A systematic literature review." Journal of Telecommunication, Electronic and Computer Engineering (JTEC) 8(3): 161-164.

Ramsden. P. (2012). Smart cities, Citizen Innovation in Smart Cities. Urbact.eu, European Union.

Skaar, J. , Bølviken, T. , Koskela, L. \& Kalsaas, B. T. 2020, 'Principles as a Bridge Between Theory and Practice' In:, Proc. 28th Annual Conference of the International Group for Lean Construction (IGLC). Berkeley, California, USA, 6-10 Jul 2020. pp 1-12.

Zimina, D., Ballard, G., \& Pasquire, C. (2012). Target value design: using collaboration and a lean approach to reduce construction cost. Construction Management and Economics, 30(5), 383-398.

UN (2017). Collection Methodology for Key Performance Indicators for Smart Sustainable Cities. unece.org, United 4 Smart Sustainable Cities.

Verma, P. and A. Raghubanshi (2018). "Urban sustainability indicators: Challenges and opportunities." Ecological indicators, 93: 282-291.

Womack, P. \& Jones, D. T. (1996). Lean Thinking. Banish waste and create wealth in your corporation, London: Simon \& Schuster.

Womack, J. P., Jones, D. T., \& Roos, D. (1990). The Machine That Changed the World, New York: Harper Collins Publishers. 